\title{
Efecto de la inclusión dietética de extracto etanólico de propóleos en la inmunidad de pollos de engorde ${ }^{\#}$
}

\author{
Effect of diet inclusion of ethanolic extract of propolis on broiler immunity
}

\author{
C Eyng ${ }^{a^{*}}$, AE Murakami ${ }^{b}$, IC Ospina-Rojas ${ }^{b}$, RB Pedroso $^{c}$, TGV Silveira $^{c}$, DAL Lourenço ${ }^{b}$ \\ aDepartamento de Zootecnia, Universidade Federal da Grande Dourados, Mato Grosso do Sul, Brasil. \\ bDepartamento de Zootecnia, Universidade Estadual de Maringá, Paraná, Brasil. \\ 'Departamento de Análises Clínicas, Universidade Estadual de Maringá, Paraná, Brasil.
}

\begin{abstract}
SUMMARY
The aim of this study was to evaluate the supplementation of ethanolic extract of propolis (EEP) in broiler chickens diets on immune responses (humoral and cellular), weight of lymphoid organs and hematological profile. A total of 192 birds, raised in metabolism cages until the 21 st day, were distributed in a completely randomised design with six treatments, eight replicates and four birds per experimental unit. The treatments consisted of diets containing $0 ; 1,000 ; 2,000 ; 3,000 ; 4,000$ and 5,000 ppm of EEP. The inclusion of EEP gave a quadratic effect $(\mathrm{P}<0.05)$ for relative weight of spleen and cloacal bursa, with the lowest weights found at the level of 2,946 ppm and 2,985 ppm of EEP, respectively. For the relative weight of thymus no change was observed $(\mathrm{P}>0.05)$. There was no change $(\mathrm{P}>0.05)$ in percentages of lymphocyte, heterophil, basophil, eosinophil and heterophil: lymphocyte ratio with the inclusion of EEP. However, there was a reduction $(\mathrm{P}<0.05)$ in the percentage of monocyte to the inclusion level of 3,000 ppm of EEP when compared to control. The phagocytic activity of macrophages, the average number of phagocytised red cells and nitric oxide production were not affected $(\mathrm{P}>0.05)$. The interdigital response to phytohaemagglutinin showed negative linear and quadratic behavior $(\mathrm{P}<0.05)$ as a function of time and levels of inclusion, respectively, noting the smallest value of the reaction with $3,074 \mathrm{ppm}$ of EEP. The birds showed a linear increase $(\mathrm{P}<0.05)$ of serum antibodies against Newcastle disease, however, when each level of inclusion was compared to the control no difference was observed $(\mathrm{P}>0.05)$. It is concluded that the addition of 1,000 to 5,000 ppm of EEP to the starter broiler diet did not have immunostimulant effect.
\end{abstract}

Key words: antibody, cellular immune response, immune system, humoral immune response.

\section{RESUMEN}

Este estudio evaluó la suplementación de extracto etanólico de propóleos (EEP) en dietas de pollos de engorde sobre la respuesta inmune (humoral y celular), peso de órganos linfoides y perfil hematológico. Se utilizaron 192 pollos de engorde, machos, criados en jaulas de metabolismo hasta los 21 días de edad. El diseño experimental fue completamente al azar con seis tratamientos, que consistieron en diferentes niveles de inclusión de EEP $(0 ; 1.000 ; 2.000 ; 3.000 ; 4.000$ y 5.000 ppm), con ocho repeticiones y cuatro aves por unidad experimental. La inclusión dietética de EEP provocó un efecto cuadrático $(\mathrm{P}<0,05)$ en el peso relativo del bazo y bolsa de Fabricio, con menores pesos en pollos suplementados con 2.946 y 2.985 ppm de EEP, respectivamente. En el peso relativo del timo no se observó efecto $(\mathrm{P}>0,05)$ de los tratamientos. La inclusión de EEP no alteró $(\mathrm{P}>0,05)$ el porcentaje de linfocitos, heterófilos, basófilos, eosinófilos y la relación heterófilo:linfocito. Hubo reducción $(\mathrm{P}<0,05)$ en el porcentaje de monocitos con la inclusión de 3.000 ppm de EEP en comparación al control. La actividad fagocítica de los macrófagos, número promedio de eritrocitos fagocitados y producción de óxido nítrico no fueron alterados $(\mathrm{P}>0,05)$. La reacción interdigital a la fitohemaglutinina presentó efecto lineal negativo y cuadrático $(\mathrm{P}<0,05)$ en función del tiempo y de los niveles de inclusión, respectivamente, resultando en menor reacción con el nivel de 3.074 ppm de EEP. Hubo aumento lineal $(\mathrm{P}<0,05)$ de los niveles de anticuerpos séricos contra la enfermedad de Newcastle al incrementar el nivel de EEP en la dieta; sin embargo, al comparar cada nivel de inclusión del extracto con el control no hubo diferencias $(\mathrm{P}<0,05)$. Se concluye que la inclusión de 1.000 a 5.000 ppm de EEP en la dieta inicial de pollos de engorde no demostró efecto inmunoestimulante.

Palabras clave: anticuerpo, respuesta inmune celular, respuesta inmune humoral, sistema inmune.

\section{INTRODUCCIÓN}

En las últimas décadas, la utilización de antibióticos como promotores de crecimiento en pollos de engorde se ha constituido en un aliado importante para mejorar los niveles de productividad y competitividad de la industria

Aceptado: 25.08.2014.

\# Investigación financiada con recursos del Conselho Nacional de Desenvolvimento Científico e Tecnológico(CNPq).

* Rodovia Dourados-Itahum, Km 12, Citade Universitária, Dourados, Mato Grosso do Sul, CEP 79804-970, Brasil; cinthiaeyng@ hotmail.com avícola. Estos aditivos impiden el metabolismo bacteriano patógeno por lo que el hospedador logra reducir la competencia por nutrientes con los microorganismos, mejorando el estatus nutricional y el rendimiento de las aves. Sin embargo, desde la prohibición del uso de los antibióticos promotores de crecimiento, en 1999, se ha observado un aumento en la incidencia de patologías digestivas y la reducción del desempeño de las aves en hasta 7\%, lo que ha repercutido en menor rentabilidad para el sector avícola (Toledo y col 2007).

Para reducir las pérdidas económicas del sector, continuamente se han estudiado alternativas nutricionales. 
Actualmente, se ha centrado la atención especial en el propóleos, producto producido por las abejas melíferas a partir de resinas y bálsamos retirados de las plantas, cera y secreciones salivares (Barth y col 1999), rico en constituyentes bioquímicos como polifenoles, flavonoides, ácidos fenólicos, aldehídos aromáticos y ésteres (Park y col 2002). Estos compuestos son capaces de potencializar elementos del sistema inmunológico (Fischer y col 2008), aumentando la resistencia a enfermedades y evitando pérdidas en el desempeño de los animales (Ziaran y col 2005). Los efectos benéficos de estas sustancias sobre el sistema inmune (humoral y celular) están relacionados con la activación de macrófagos, síntesis de anticuerpos, mayor actividad de linfocitos natural killer, aumento de peso de los órganos linfoides, entre otros (Orsi y col 2000, Taheri y col 2005, Fischer y col 2008, Çetin y col 2010). Además de estos efectos directos, una serie de compuestos del propóleos pueden actuar indirectamente sobre el sistema inmunológico, ya que poseen diversas actividades biológicas, como antioxidante, antifúngica, antiinflamatoria y principalmente antimicrobiana (Fernandes Jr y col 2006, Lustosa y col 2008, Cabral y col 2009). En este contexto, el propóleos, mediante la acción antimicrobiana, puede modular la microflora intestinal, y de este modo, estimular y regular varios aspectos del sistema inmune (Haghighi y col 2005, Fonseca y Costa 2010), responsables de la maduración del mismo (Chung y Kasper 2010). Se reporta que una rápida colonización bacteriana después del nacimiento está asociada a la producción de anticuerpos por el organismo (Suzuki y col 2007).

De esta forma, el objetivo de este estudio fue evaluar la eficacia de la suplementación de extracto etanólico de propóleos (EEP) en dietas de pollos de engorde sobre la respuesta inmune (humoral y celular), peso de órganos linfoides y perfil hematológico.

\section{MATERIAL Y MÉTODOS}

\section{ANIMALES Y DISEÑO EXPERIMENTAL}

Se utilizaron 192 pollos de engorde de un día de edad de la línea comercial Cobb-Vantress, machos, criados en jaulas de metabolismo hasta los 21 días de edad. El diseño experimental fue completamente al azar con seis tratamientos, que consistieron en diferentes niveles de inclusión del EEP $(0 ; 1.000 ; 2.000 ; 3.000 ; 4.000$ y 5.000 ppm) en las dietas, con ocho repeticiones y cuatro aves por unidad experimental. El tratamiento control ( 0 ppm) no contenía ningún tipo de aditivo. Las dietas experimentales fueron formuladas para atender las exigencias nutricionales propuestas por Rostagno y col (2005) para las fases de 1 a 7 y 8 a 21 días de edad (cuadro 1).

\section{EXTRACTO ETANÓLICO DE PROPÓLEOS}

El EEP se preparó al 50\% (P/V) de propóleos y alcohol etílico. El EEP se adquirió en Maringá-PR, Brasil, y se
Cuadro 1. Composición porcentual y calculada de las raciones experimentales.

Percent and calculate composition of experimental diets.

\begin{tabular}{lcc}
\hline & \multicolumn{2}{c}{ Fases (días) } \\
\cline { 2 - 3 } Ingredientes (\%) & 1 a 7 & 8 a 21 \\
\hline Maíz & 55,75 & 58,63 \\
Harina de soya, 45\% & 37,04 & 34,39 \\
Aceite de soya & 2,20 & 2,51 \\
Calcáreo & 0,92 & 0,88 \\
Fosfato bicálcico & 1,94 & 1,80 \\
Sal común & 0,40 & 0,40 \\
Inerte* & 0,50 & 0,50 \\
DL- Metionina, 98\% & 0,36 & 0,24 \\
L- Lisina HCl, 78\% & 0,35 & 0,19 \\
L- Treonina, 98\% & 0,15 & 0,05 \\
Suplemento mineral y vitamínico & 0,40 & 0,40 \\
Total & 100 & 100 \\
\hline Valores calculados & & \\
\hline Proteína cruda (\%) & 22,04 & 20,79 \\
Energía metabolizable (kcal/kg) & 2950 & 3000 \\
Calcio (\%) & 0,939 & 0,884 \\
Fósforo disponible (\%) & 0,470 & 0,442 \\
Met + Cis, dig (\%) & 0,944 & 0,814 \\
Lisina, dig (\%) & 1,330 & 1,146 \\
Treonina, dig (\%) & 0,865 & 0,745 \\
Triptofano, dig (\%) & 0,213 & 0,183 \\
\hline
\end{tabular}

1 Suplemento vitamínico (contenido/kg de premezcla): Vit. A 2.916 .670 UI/kg; Vit. D3 583.330 UI/kg; Vit. E 8.750 UI/kg; Vit. K3 433,33 $\mathrm{mg} / \mathrm{kg}$; Vit. B1 408,33 mg/kg; Vit. B2 1.333,33 mg/kg, Vit. B12 4.166,67 mcg/kg; Niacina 8.983,33 mg/kg; Pantotenato de calcio $3.166,67 \mathrm{mg} / \mathrm{kg}$; Ácido Fólico $200 \mathrm{mg} / \mathrm{kg}$; Biotina $25 \mathrm{mg} / \mathrm{kg}$. Suplemento Mineral (contenido/kg de premezcla): Hierro 12,6 g/kg; Cobre $3.072 \mathrm{mg} / \mathrm{kg}$; Yodo $248 \mathrm{mg} / \mathrm{kg}$; Zinc 12,6 g/kg; Manganeso $15 \mathrm{~g} / \mathrm{kg}$; Selenio $61,20 \mathrm{mg} / \mathrm{kg}$; Cobalto $50,40 \mathrm{mg} / \mathrm{kg}$.

* El extracto etanólico de propóleos fue adicionado en las raciones en sustitución al inerte.

1 Vitamin Supplement (content/kg of premix): Vit. A 2.916.670 UI/kg; Vit. D3 583.330 UI/kg; Vit. E 8.750 UI/kg; Vit. K3 433.33 mg/kg; Vit. B1 $408.33 \mathrm{mg} /$ kg; Vit. B2 1.333,33 mg/kg, Vit. B12 4.166,67 mcg/kg; Niacin 8.983,33 mg/ kg; Calcium pantothenate $3.166,67 \mathrm{mg} / \mathrm{kg}$; Folic acid $200 \mathrm{mg} / \mathrm{kg}$; Biotin 25 $\mathrm{mg} / \mathrm{kg}$. Mineral Supplement (content $/ \mathrm{kg}$ of premix): Iron $12.6 \mathrm{~g} / \mathrm{kg}$; Cooper $3.072 \mathrm{mg} / \mathrm{kg}$; Iodine $248 \mathrm{mg} / \mathrm{kg}$; Zinc $12.6 \mathrm{~g} / \mathrm{kg}$; Manganese $15 \mathrm{~g} / \mathrm{kg}$; Selenium $61.20 \mathrm{mg} / \mathrm{kg}$; Cobalt $50.40 \mathrm{mg} / \mathrm{kg}$.

* The ethanolic extract of propolis was added to the diets as an inert replacement.

conservó en temperatura entre 2 y $8{ }^{\circ} \mathrm{C}$ hasta el momento de utilización. La determinación de los polifenoles totales (Singleton y Rossi 1965, Pierpoint 2004) y flavonoides totales se realizó en el Laboratorio de Tecnología de Productos Agropecuarios-UEM.

\section{PERFIL HEMATOLÓGICO Y COLECTA DE ÓRGANOS} LINFOIDES

A los 21 días de edad se seleccionaron seis aves de cada tratamiento, con peso representativo (media $\pm 5 \%$ ), 
para determinar el perfil hematológico y el peso relativo (\% del peso vivo) de los órganos linfoides (bolsa de Fabricio, bazo y timo). Para determinar el perfil hematológico se preparó un frotis sanguíneo en láminas de vidrio y se tiñó con May Grünwald-Giemsa. Se realizó el conteo diferencial de linfocitos, heterófilos, eosinófilos, monocitos y basófilos en microscopio óptico con objetivo de inmersión, calculándose la proporción de cada glóbulo blanco en 100 células contadas/ave.

ACTIVIDAD FAGOCÍTICA DE MACRÓFAGOS ABDOMINALES Y PRODUCCIÓN DE ÓXIDO NÍTRICO

Se utilizaron cinco aves por tratamiento para evaluar la actividad fagocítica de macrófagos abdominales, conforme a lo descrito por Qureshi y col (1986). A los 21 días de edad, las aves fueron inyectadas intraperitonealmente con Sephadex G-50 ${ }^{\circledR}$ (Sigma) al 3\% en solución salina al 0,9\% ( $1 \mathrm{~mL}$ por cada $100 \mathrm{~g}$ de peso corporal).

Después de 42 horas, las aves se sacrificaron por dislocación cervical y se realizó el proceso de limpieza (detergente neutro) y sanitización (alcohol al 70\%) del abdomen con posterior inoculación de $20 \mathrm{~mL}$ de PBS (tampón fosfato salino) estéril heparinizado $\left(0,5 \mathrm{U} / \mathrm{mL}\right.$ marca Liquemine ${ }^{\circledR}$ Roche). En seguida se recolectaron aproximadamente $15 \mathrm{~mL}$ de este líquido abdominal, e inmediatamente fue almacenado en tubos plásticos mantenidos en hielo. El material colectado se centrifugó a 1.500 rpm durante 10 minutos y el pellet obtenido fue resuspendido en $1 \mathrm{~mL}$ del medio de cultivo RPMI $164{ }^{\circledR}$ (Sigma). Posteriormente, se sembró $150 \mu \mathrm{L}$ de esta suspensión celular en placas de cultivo de 24 orificios con cubreobjetos de vidrio de 13 $\mathrm{mm}$ de diámetro y tras una hora de incubación en estufa a $37^{\circ} \mathrm{C}$ con $5 \%$ de $\mathrm{CO}_{2}$, se lavó cada orificio con solución RPMI 1640, para remover las células no adheridas. A continuación, las células adheridas se desafiaron con $200 \mu \mathrm{L}$ de eritrocitos de carnero (suspensión de 3\% de eritrocitos en medio RPMI 1640) y se incubaron nuevamente por 1 hora. Al final de la incubación se lavó cada orificio con el medio RPMI 1640 y se realizó la tinción utilizando un kit comercial (Panótico Rápido LB ${ }^{\circledR}$-Laborclin).

Después del secado y fijación del cubreobjetos en las láminas de vidrio se realizó el conteo de por lo menos 200 macrófagos, en triplicado para cada animal, observándose el número de macrófagos con eritrocitos fagocitados y el número de eritrocitos en cada macrófago. La actividad fagocítica se calculó considerando el número de macrófagos con eritrocitos fagocitados dividido por el número total de macrófagos contados.

Para determinar la producción de óxido nítrico de los macrófagos se realizó simultáneamente una segunda placa que siguió los mismos pasos descritos anteriormente hasta el segundo lavado de los orificios. Esta placa se incubó por 24 horas a $37{ }^{\circ} \mathrm{C}$ con $5 \%$ de $\mathrm{CO}_{2}$, y se determinó la producción de óxido nítrico, midiéndose la concentración de nitritos en el sobrenadante mediante la reacción de
Griess, conforme la metodología descrita por Qureshi y col (1986). Se utilizó como control positivo los macrófagos y los glóbulos rojos $(\mathrm{M} \varnothing+\mathrm{hc})$ y como control negativo los macrófagos (MØ).

\section{RESPUESTA INMUNE MEDIADA POR CÉLULAS IN VIVO}

Se seleccionaron seis aves de cada tratamiento a los 21 días de edad para evaluar la respuesta inmune mediada por células in vivo, conforme a lo descrito por Corrier y DeLoach (1990). Las aves fueron inyectadas intradérmicamente con $0,1 \mathrm{~mL}$ de fitohemaglutinina PHA-M ${ }^{\circledR}$ (Invitrogen), entre el $3^{\circ}$ y $4^{\circ}$ pliegue interdigital de la pata derecha. El mismo volumen de solución salina se aplicó en la pata izquierda, como control negativo. El engrosamiento de la piel en ambas patas se midió con auxilio de un parquímetro digital, antes de la inoculación y 12, 24, 48 y 72 horas después. Los resultados fueron obtenidos por la diferencia entre la respuesta a la fitohemaglutinina y la respuesta del control, en los diferentes tiempos.

\section{TÍTULOS DE ANTICUERPOS}

Las aves se vacunaron el $14^{\circ}$ día de vida contra la enfermedad de Newcastle y a los 21 días se colectaron muestras de sangre de seis aves por tratamiento. El suero se separó de la muestra y se utilizó para medir la producción de anticuerpos contra la enfermedad de Newcastle por medio del kit de ELISA indirecto (IDEXX ${ }^{\odot}$ ). Los títulos evaluados fueron referentes a la respuesta a la vacunación.

\section{ANÁLISIS ESTADÍSTICO}

Los resultados del peso relativo de los órganos linfoides, actividad de macrófagos y título de anticuerpos se sometieron a análisis de varianza y regresión polinomial mediante el programa SAEG-Sistemas de Análises Estatísticas e Genéticas (Saeg 1997).

Los valores hematológicos se analizaron con el test de Shapiro-Wilk para verificar la normalidad de los datos y las variables con distribución normal se sometieron a análisis de varianza y regresión lineal simple, mientras que las demás variables se analizaron por medio de modelos lineales generalizados, utilizándose distribución Gamma con función de ligación inversa. Para la reacción interdigital a la fitohemaglutinina también se realizó el test de Shapiro-Wilk y las variables con distribución normal fueron sometidas a análisis de varianza y regresión lineal múltiple, considerando el tiempo y los niveles de inclusión del EEP, siendo los resultados presentados por medio de un gráfico de superficie respuesta. Ambos análisis se realizaron mediante el programa $\mathrm{R}(R$ Development Core Team 2009).

Para comparar los resultados del control y los niveles de inclusión de EEP se utilizó el test de Dunnett al 5\% de probabilidad. Para evaluar el efecto del tiempo entre las 
diferentes mediciones mediante la reacción interdigital a la fitohemaglutinina se aplicó el test de Tukey al 5\% de probabilidad.

\section{PROTOCOLO DE EXPERIMENTACIÓN ANIMAL}

El protocolo de experimentación animal utilizado fue previamente aprobado por el Comité de Conducta Ética para el Uso de Animales en Experimentación de la Universidad Estatal de Maringá-UEM (Parecer Nº 048/2010).

\section{RESULTADOS}

La concentración de polifenoles y flavonoides totales encontrados en el EEP fue de $357,71 \mathrm{mg} / \mathrm{L}$ y 112,72 $\mathrm{mg} / \mathrm{L}$, respectivamente. Teniendo en cuenta los niveles de inclusión de EEP $(1.000 ; 2.000 ; 3.000 ; 4.000$ y 5.000 ppm) utilizados en el presente estudio, las aves recibieron 5,$64 ; 11,27 ; 16,91 ; 22,54$ y $28,18 \mathrm{mg}$ de flavonoides por $\mathrm{kg}$ de ración, respectivamente.

Se observó efecto cuadrático $(\mathrm{P}<0,05)$ de los niveles de EEP sobre el peso relativo del bazo y bolsa de Fabricio a los 21 días de edad, siendo estimados menores pesos con 2.946 ppm y 2.985 ppm de EEP, respectivamente. Sin embargo, al comparar cada nivel de EEP con el grupo control $(0 \mathrm{ppm})$ no se encontraron diferencias $(\mathrm{P}>0,05)$ en el peso relativo de estos órganos. Igualmente, los niveles de EEP no afectaron $(\mathrm{P}>0,05)$ el peso relativo del timo (cuadro 2).

En los resultados del perfil hematológico se observó que los niveles de EEP no influenciaron $(\mathrm{P}>0,05)$ el conteo de linfocitos, heterófilos, basófilos, eosinófilos y la relación heterófilo:linfocito. Sin embargo, los pollos que recibieron la inclusión de 3.000 ppm de EEP presentaron menor $(\mathrm{P}<0,05)$ porcentaje de monocitos, comparado con los pollos alimentados con el grupo control (cuadro 3).

La inclusión de EEP en las dietas no afectó $(\mathrm{P}>0,05)$ la actividad fagocítica de los macrófagos, número de eritrocitos fagocitados y producción de óxido nítrico de los pollos de engorde a los 21 días de edad (cuadro 4).

Para la respuesta celular interdigital cutánea tras la inyección de fitohemaglutinina, no se observó interacción $(\mathrm{P}>0,05)$ entre los factores tratamiento y tiempo de reacción. El análisis de varianza indicó efecto del tiempo ( $\mathrm{P}$ $<0,05$ ) sobre esta variable (cuadro 5). Se observó efecto lineal $(\mathrm{P}<0,05)$ en función del tiempo y cuadrático $(\mathrm{P}<$ $0,05)$ en función de los niveles de EEP. De acuerdo con la ecuación ajustada, el nivel de 3.074 ppm de EEP resultó en el menor valor de la reacción (figura 1).

Los títulos séricos de anticuerpos producidos por la vacunación contra la enfermedad de Newcastle a los 21 días de edad aumentaron linealmente $(\mathrm{P}<0,05)$ según aumentó el nivel de inclusión de EEP. Sin embargo, al comparar los títulos de anticuerpos de las aves que recibieron las dietas con EEP y aves alimentadas con la dieta control, no se encontraron diferencias estadísticamente significativas $(\mathrm{P}>0,05)$ (cuadro 6).

\section{DISCUSIÓN}

El EEP utilizado en este trabajo presentó mayor concentración de polifenoles y flavonoides totales, en comparación con los extractos usados en otros estudios en los que determinaron su composición química (Silva y col 2006, Sousa y col 2007, Buriol y col 2009).

Los trabajos encontrados en la literatura con pollos de engorde (Shalmany y Shivazad 2006, Tatli Seven y col 2008, Tatli Seven y col 2009, Tekeli y col 2010) no

Cuadro 2. Peso relativo \pm EE $(\%)$ de timo, bazo y bolsa de Fabricio de pollos de engorde a los 21 días de edad, alimentados con dietas conteniendo diferentes niveles de extracto etanólico de propóleos (EEP).

Relative weights \pm SD $(\%)$ of thyme, spleen and bursa Fabricius of broiler chickens at 21 days of age fed diets with different levels of ethanolic extract of propolis (EEP).

\begin{tabular}{lccc}
\hline Niveles de EEP & Timo & Bazo & Bolsa de Fabricio \\
\hline Control & $0,415 \pm 0,04$ & $0,128 \pm 0,01$ & $0,229 \pm 0,01$ \\
$1000 \mathrm{ppm}$ & $0,380 \pm 0,04$ & $0,146 \pm 0,01$ & $0,280 \pm 0,03$ \\
$2000 \mathrm{ppm}$ & $0,525 \pm 0,04$ & $0,121 \pm 0,01$ & $0,226 \pm 0,01$ \\
$3000 \mathrm{ppm}$ & $0,432 \pm 0,03$ & $0,116 \pm 0,01$ & $0,199 \pm 0,02$ \\
$4000 \mathrm{ppm}$ & $0,395 \pm 0,02$ & $0,134 \pm 0,01$ & $0,242 \pm 0,02$ \\
$5000 \mathrm{ppm}$ & $0,453 \pm 0,02$ & $0,142 \pm 0,01$ & $0,275 \pm 0,02$ \\
CV $(\%)$ & 18,49 & 18,33 & 19,99 \\
Regresión & $\mathrm{ns}$ & Cuadrático $^{1}(\mathrm{P}<0,03)$ & Cuadrático $^{2}(\mathrm{P}<0,004)$ \\
\hline
\end{tabular}

No significativo por el test de Dunnett $(\mathrm{P}>0,05)$.

Not significant by Dunnett test $(\mathrm{P}>0,05)$.

$\mathrm{ns}=$ no significativo.

ns $=$ not significant

${ }^{1} \mathrm{Y}=0,173797-0,000037413 \mathrm{x}+0,00000000635 \mathrm{x}^{2}\left(\mathrm{R}^{2}=0,84\right)$; Punto de mínima: 2946 ppm.

${ }^{1} \mathrm{Y}=0,173797-0,000037413 \mathrm{x}+0,00000000635 \mathrm{x} 2(\mathrm{R} 2=0,84)$; Minimum point: $2946 \mathrm{ppm}$.

${ }^{2} \mathrm{Y}=0,364969-1,04227 \mathrm{x}+1,74600 \mathrm{x}^{2}\left(\mathrm{R}^{2}=0,92\right)$; Punto de mínima: $2985 \mathrm{ppm}$.

${ }^{2} \mathrm{Y}=0,364969-1,04227 \mathrm{x}+1,74600 \times 2(\mathrm{R} 2=0,92)$; Minimum point: $2985 \mathrm{ppm}$. 
Cuadro 3. Valores hematológicos (\%) y relación heterófilo:linfocito (H:L) \pm error EE de pollos de engorde a los 21 días de edad, alimentados con dietas conteniendo diferentes niveles de extracto etanólico de propóleos (EEP).

Hematological values $(\%)$ and heterophil:lymphocyte ratio $(\mathrm{H}: \mathrm{L}) \pm \mathrm{SD}$ of broiler chickens at 21 days of age fed diets with different levels of ethanolic extract of propolis (EEP).

\begin{tabular}{lcccccc}
\hline Niveles de EEP & Linfocito & Heterófilo & Basófilo & Monocito & Eosinófilo & Relación H:L \\
\hline Control & $56,80 \pm 0,98$ & $26,94 \pm 2,32$ & $7,90 \pm 2,32$ & $1,72 \pm 0,45$ & $6,64 \pm 1,57$ & $0,48 \pm 0,04$ \\
$1000 \mathrm{ppm}$ & $67,08 \pm 1,08$ & $20,48 \pm 2,85$ & $7,34 \pm 1,18$ & $1,93 \pm 1,18$ & $3,18 \pm 0,82$ & $0,31 \pm 0,04$ \\
$2000 \mathrm{ppm}$ & $58,89 \pm 1,28$ & $27,84 \pm 1,67$ & $6,02 \pm 1,85$ & $0,95 \pm 0,03$ & $6,49 \pm 0,51$ & $0,47 \pm 0,03$ \\
$3000 \mathrm{ppm}$ & $61,60 \pm 3,12$ & $25,85 \pm 3,55$ & $6,67 \pm 0,96$ & $0,00 \pm 0,00 *$ & $5,68 \pm 0,56$ & $0,44 \pm 0,08$ \\
$4000 \mathrm{ppm}$ & $58,12 \pm 1,93$ & $25,57 \pm 1,55$ & $10,26 \pm 0,49$ & $1,16 \pm 0,37$ & $4,88 \pm 0,74$ & $0,44 \pm 0,04$ \\
$5000 \mathrm{ppm}$ & $61,11 \pm 2,66$ & $27,12 \pm 2,93$ & $5,70 \pm 0,84$ & $0,98 \pm 0,31$ & $5,10 \pm 0,82$ & $0,45 \pm 0,07$ \\
CV $(\%)$ & 8,69 & 21,62 & 42,19 & 102,71 & 37,22 & 28,14 \\
Regresión & $\mathrm{ns}$ & $\mathrm{ns}$ & $\mathrm{ns}$ & $\mathrm{ns}$ & $\mathrm{ns}$ & $\mathrm{ns}$
\end{tabular}

*Significativo por el test de Dunnett $(\mathrm{P}<0,05)$.

Significant by Dunnett test $(\mathrm{P}<0,05)$.

ns $=$ no significativo

ns $=$ not significant.

Cuadro 4. Actividad fagocítica (\%), eritrocitos fagocitados y concentración de óxido nítrico $(\mu \mathrm{M} / \mathrm{mL}) \pm$ EE de pollos de engorde con 21 días de edad, alimentados con dietas conteniendo diferentes niveles de extracto etanólico de propóleos (EEP).

Table 4. Phagocytic activity (\%), phagocytosed erythrocytes and nitric oxide concentration $(\mu \mathrm{M} / \mathrm{mL}) \pm$ SD of broiler chickens at 21 days of age fed diets with different levels of ethanolic extract of propolis (EEP).

\begin{tabular}{|c|c|c|c|c|}
\hline \multirow{2}{*}{ Niveles de EEP } & \multirow{2}{*}{ Actividad fagocítica } & \multirow{2}{*}{ Eritrocitos fagocitados } & \multicolumn{2}{|c|}{ Óxido nítrico } \\
\hline & & & $\mathrm{M} \varnothing+\mathrm{hc}^{1}$ & $\mathrm{M} \varnothing^{2}$ \\
\hline Control & $25,36 \pm 1,23$ & $4,31 \pm 0,09$ & $16,70 \pm 2,36$ & $4,67 \pm 1,21$ \\
\hline $1000 \mathrm{ppm}$ & $24,18 \pm 3,88$ & $4,56 \pm 0,29$ & $24,58 \pm 5,50$ & $8,06 \pm 2,85$ \\
\hline $2000 \mathrm{ppm}$ & $21,97 \pm 3,44$ & $5,10 \pm 0,21$ & $14,88 \pm 0,69$ & $2,70 \pm 0,05$ \\
\hline $3000 \mathrm{ppm}$ & $19,47 \pm 1,50$ & $5,00 \pm 0,47$ & $17,04 \pm 3,09$ & $5,99 \pm 1,63$ \\
\hline $4000 \mathrm{ppm}$ & $24,15 \pm 1,80$ & $4,97 \pm 0,11$ & $21,20 \pm 5,82$ & $5,56 \pm 1,90$ \\
\hline $5000 \mathrm{ppm}$ & $24,77 \pm 0,52$ & $4,80 \pm 0,13$ & $18,97 \pm 1,52$ & $5,70 \pm 1,08$ \\
\hline $\mathrm{CV}(\%)$ & 22,75 & 10,75 & 45,04 & 70,14 \\
\hline Regresión & ns & ns & ns & ns \\
\hline
\end{tabular}

${ }^{1}$ Control positivo $=$ macrófagos + eritrocitos.

${ }^{1}$ Positive control $=$ macrophages + erythrocytes.

${ }^{2}$ Control negativo $=$ macrófagos

${ }^{2}$ Negative control $=$ macrophages.

No significativo por el test de Dunnett $(\mathrm{P}>0,05)$.

Not significant by Dunnett test $(\mathrm{P}>0,05)$.

ns $=$ no significativo.

ns $=$ not significant.

relacionan los niveles utilizados de EEP con la concentración de los compuestos biológicamente activos (flavonoides). La concentración de estos compuestos puede variar entre las muestras de propóleos de acuerdo con la flora local, características climáticas y geográficas, así como también por la genética de las abejas (Bankova 2005). Por lo tanto, la estandarización de los niveles de EEP a partir de la concentración de flavonoides, sería una estrategia para minimizar esta variación.

El peso relativo de los órganos linfoides es un parámetro utilizado para predecir el estatus inmunitario del animal (Chichlowski y col 2007, Ashayerizadeh y col 2009). Así, los menores pesos del bazo y bolsa de Fabricio encontrados con el nivel de inclusión de 2.946 ppm y 2.985 ppm de EEP, respectivamente, podrían indicar mayor susceptibilidad de los animales a patógenos. Sin embargo, como el peso de los órganos linfoides es un parámetro inmunitario secundario, este debe ser correlacionado con las demás medidas de inmunidad. Además, Kabir y col (2004) afirmaron que la bolsa de Fabricio es responsable por la maduración de los linfocitos B y de esta forma el peso relativo del órgano no debe ser considerado aisladamente, debiéndose correlacionar con la producción de anticuerpos.

El conteo diferencial de los componentes celulares también es un dato complementario para evaluar las respuestas inmunológicas de los animales (Cardoso y 
Cuadro 5. Reacción interdigital a la fitohemaglutinina $(\mathrm{mm}) \pm$ EE en pollos de engorde con 21 días de edad, alimentados con dietas conteniendo diferentes niveles de extracto etanólico de propóleos (EEP).

Interdigital reaction to phytohemagglutinin $(\mathrm{mm}) \pm \mathrm{SD}$ of broiler chickens at 21 days of age fed diets with different levels of ethanolic extract of propolis (EEP)

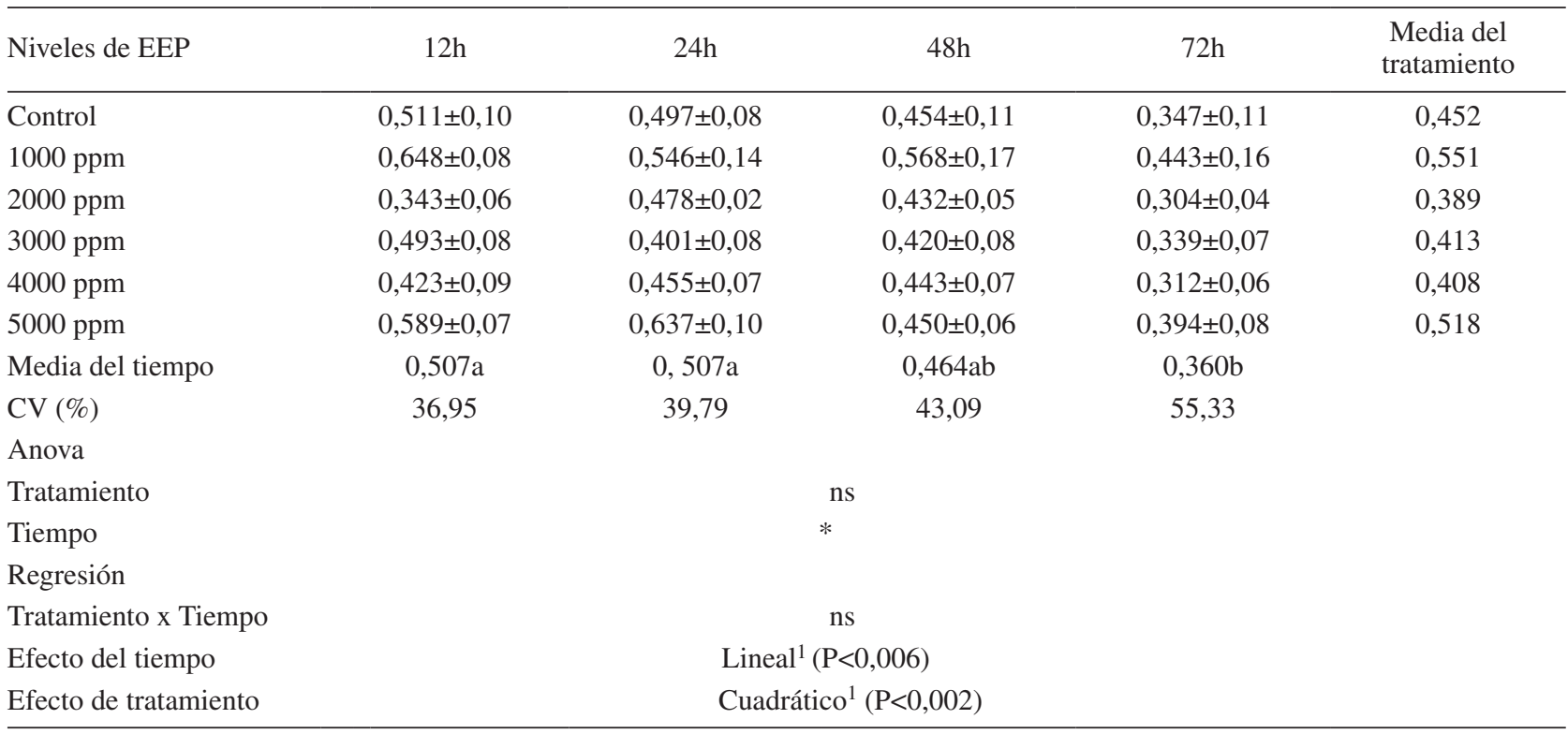

ns $=$ no significativo.

$\mathrm{ns}=$ not significant

*Medias seguidas por letras diferentes, en la misma línea, difieren entre sí por el test de Tukey $(\mathrm{P}<0,05)$.

* Means followed by different letters in the same row differ by Tukey test $(\mathrm{P}<0,05)$.

${ }^{1} \mathrm{Y}=0,8273576-0,0024361 *$ hora $-0,00022816680 *$ nivel $+0,000000037106326 *$ nivel $^{2}\left(\mathrm{R}^{2}=0,73\right)$

${ }^{1} \mathrm{Y}=0,8273576-0,0024361 *$ hour $-0,00022816680 *$ level $+0,000000037106326 * \mathrm{level}^{2}\left(\mathrm{R}^{2}=0,73\right)$.

Cuadro 6. Título de anticuerpos $\left(\log _{10}\right) \pm \mathrm{EE}$ de pollos de engorde con 21 días de edad, alimentados con dietas con diferentes niveles de extracto etanólico de propóleos (EEP).

Antibody titer $\left(\log _{10}\right) \pm \mathrm{SD}$ of broiler chickens at 21 days of age fed diets with different levels of ethanolic extract of propolis (EEP).

\begin{tabular}{lc}
\hline Niveles de inclusión de EEP & Título \\
\hline Control & $2,535 \pm 0,03$ \\
$1000 \mathrm{ppm}$ & $2,448 \pm 0,09$ \\
$2000 \mathrm{ppm}$ & $2,375 \pm 0,11$ \\
$3000 \mathrm{ppm}$ & $2,438 \pm 0,01$ \\
$4000 \mathrm{ppm}$ & $2,663 \pm 0,06$ \\
$5000 \mathrm{ppm}$ & $2,625 \pm 0,04$ \\
CV $(\%)$ & 6,13 \\
Regresión & Lineal $^{1}(\mathrm{P}<0,014)$ \\
\hline
\end{tabular}

No significativo por test de Dunnett $(\mathrm{P}>0,05)$.

Non significant by Dunnett test $(\mathrm{P}>0,05)$.

ns $=$ no significativo

$\mathrm{ns}=$ non significant

${ }^{1} \mathrm{Y}=2,32002+0,0000641850 x\left(\mathrm{R}^{2}=0,66\right)$.

Tessari 2003), siendo indicador de la influencia de la nutrición y suplementación de aditivos en las dietas sobre el organismo animal (Toghyani y col 2010). Como se observaron pequeñas diferencias estadísticas para los monocitos, no existe evidencia suficiente para deducir

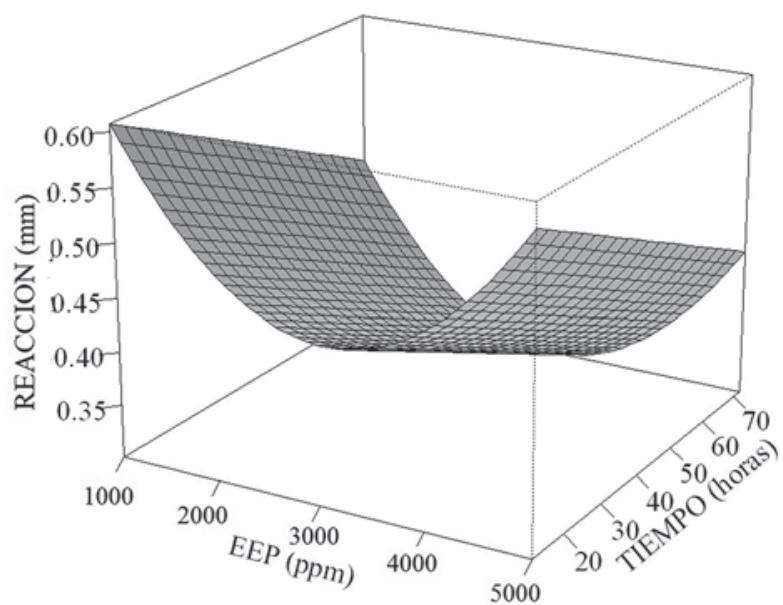

Figura 1. Superficie de respuesta para la reacción interdigital a la fitohemaglutinina en función del nivel de inclusión de extracto etanólico de propóleos (EEP) y el tiempo del análisis en pollos de engorde a los 21 días de edad alimentados con raciones conteniendo diferentes niveles de EEP.

Response surface of interdigital reaction to phytohemagglutinin $(\mathrm{mm})$ as a function of level of inclusion of ethanolic extract of propolis (EEP) and analysis time of broiler chickens at 21 days of age fed diets with different levels of EEP. 
que la inclusión del EEP modificó los parámetros hematológicos de las aves. De la misma forma, Shahryar y col (2011), trabajando con EEP, observaron una tendencia a reducir el porcentaje de monocitos con el aumento de los niveles de inclusión.

En la literatura existen resultados controvertidos en cuanto a la influencia del EEP sobre los parámetros hematológicos. Diversos autores reportaron que la inclusión de EEP mejora la inmunidad de las aves al aumentar los linfocitos y reducir los heterófilos (Ziaran y col 2005, Abd El-Motaal y col 2008, Galal y col 2008 a,b) mientras que otros no reportan modificaciones en el conteo diferencial de células (Çetin y col 2010).

El porcentaje de linfocitos y heterófilos encontrado en este trabajo es semejante a los citados en la literatura, no obstante, los eosinófilos y basófilos están por encima, en cuanto que los monocitos están por debajo de los valores de referencia publicados (Cardoso y Tessari 2003, Laganá y col 2005). Diversos factores pueden interferir en el perfil hematológico como: la alimentación, genética, temperatura, estatus sanitario, entre otros, lo que explicaría las diferencias encontradas (Borsa 2009).

Varios estudios han demostrado que los compuestos presentes en el propóleos pueden activar los macrófagos (Dimov y col 1991, Orsi y col 2005), modular la producción de óxido nítrico por estas células (Missima y Sforcin 2008, Araújo y col 2010) y amplificar la respuesta inmune humoral (Ansorge y col 2003).

Estos compuestos benéficos son dosis-dependiente, pudiendo en altas concentraciones inhibir ciertos eventos inmunológicos (Orsi y col 2005) así como también pueden originar beneficios al organismo cuando el sistema inmune está deprimido (Fischer y col 2008). De esta forma, los niveles utilizados en el experimento, aunado a la mayor concentración del extracto (50\% de propóleos y $50 \%$ de alcohol etílico) pueden ser los responsables de que los animales no hubieran expresado mejores resultados.

El test de la fitohemaglutinina evalúa la inmunidad mediada por células, siendo la respuesta linfocito-T dependiente (Galal y col 2008 ${ }^{\mathrm{b}}$ ). De esta forma, la fitohemaglutinina presenta capacidad mitogénica, siendo capaz de inducir el aumento de la población de linfocitos, ocurriendo el acúmulo de estas células y la infiltración de macrófagos 24 horas después del inicio de la respuesta cutánea (McCorkle y col 1980). Este test también es llamado de reacción de hipersensibilidad basófila cutánea por tener los basófilos asociados en esas reacciones (Cardoso y Tessari 2003).

A pesar de que la máxima respuesta ocurre 24 horas después, se observaron valores semejantes entre 12 y 24 horas postinoculación, evidenciando una respuesta precoz independiente del nivel de inclusión de EEP, demostrando que los animales presentaban un sistema inmune funcionalmente activo. De la misma forma, Ferreira y col (2009) detectaron una respuesta inflamatoria temprana, cuya reacción se observó tres horas después de la aplicación de fitohemaglutinina. La reducción de la respuesta interdigital con el tiempo postinoculación, era un resultado esperado, efecto debido a la regulación de los eventos fisiológicos inflamatorios una vez neutralizado el estímulo lesivo.

El EEP presenta actividad adyuvante (inmunopotenciadora), mostrando ser capaz de aumentar y prolongar la respuesta inmunológica contra los antígenos vacunales (Fischer y col 2010). Los compuestos biológicamente activos del propóleos pueden aumentar la producción de citocinas por los macrófagos, estas moléculas estimulan la producción de linfocitos $\mathrm{B}$, siendo posible la posterior síntesis de anticuerpos (Taheri y col 2005). Aunque los niveles de EEP influenciaron el peso relativo de la bolsa de Fabricio, reduciendo su peso hasta el nivel de 2.985 ppm y no alteraron la actividad fagocítica de los macrófagos, se evidenció un incremento lineal en la producción de anticuerpos según aumentó el nivel de inclusión de EEP. Kong y col (2006) verificaron que solamente 21 días después de la administración de la vacuna de Newcastle, los animales presentaron mayores títulos de anticuerpos. Posiblemente, si se hubiese medido la producción de anticuerpos 21 días postvacunación y no en siete días, podrían haber sido observados mayores títulos de anticuerpos, con diferencia entre los tratamientos con inclusión de EEP y el grupo control.

La acción del EEP sobre la respuesta inmune celular y humoral depende del tipo y cantidad de propóleos, composición química, dietas experimentales, edad y peso del animal (Çetin y col 2010), siendo estos factores responsables por los resultados divergentes encontrados entre los estudios.

Se concluye que la inclusión de 1.000 a 5.000 ppm de extracto etanólico de propóleos en la dieta inicial de pollos de engorde no proporcionó acción inmunoestimulante.

\section{REFERENCIAS}

Abd el-motaal AM, AMH Ahmed, ASA Bahakaim, MM Fathi. 2008. Productive performance and immunocompetence of commercial laying hens given diets supplemented with eucalyptus. Int J Poult Sci 7, 445-449.

Ansorge S, D Reinhold, U Lendeckel. 2003. Propolis and some of its constituents down-regulate DNA synthesis and inflammatory cytokine production but induce TGF- $\beta 1$ production of human immune cells. Zeits Naturfor 58c, 580-589.

Araújo MJAM, RP Dutra, GC Costa, AS Reis, AKM Assunção, AS Libério, MCG Maciel, LA Silva, RNM Guerra, MNS Ribeiro, FRF Nascimento. 2010. Efeito do tratamento com própolis de Scaptotrigona aff. postica sobre o desenvolvimento do tumor de Ehrlich em camundongos. Rev Bras Farmacogn 20, 580-587.

Ashayerizadeh O, B Dastar, M Shams Shargh, A Ashayerizadeh, M Mamooee. 2009. Influence of antibiotic, prebiotic and probiotic supplementation to diets on carcass characteristics, hematological indices and internal organ size of young broiler chickens. J Anim Vet Adv 8, 1772-1776.

Bankova V. 2005. Recent trends and important developments in propolis research. $e C A M 2,29-32$.

Barth OM, VML Dutra, RL Justo. 1999. Análise polínica de algumas amostras de própolis do Brasil Meridional. Cienc Rural 29, 663-667.

Borsa A. 2009. Valores hematológicos em frangos de corte de criação industrial. Colloquium Agrariae 5, 25-31. 
Buriol L, D Finger, EM Schmidt, JMT Santos, MR Rosa, SP Quináia, YR Torres, HSD Santa, C Pessoa, MO Moraes, LV Costa-Lotufo, PMP Ferreira, ACHF Sawaya, MN Eberlin. 2009. Composição química e atividade biológica de extrato oleoso de própolis: uma alternativa ao extrato etanólico. Quím Nova 32, 296-302.

Cabral ISR, TLC Oldoni, A Prado, RMN Bezerra, SM Alencar. 2009. Composição fenólica, atividade antibacteriana e antioxidante da própolis vermelha brasileira. Quím Nova 32, 1523-1527.

Cardoso ALSP, ENC Tessari. 2003. Estudo dos parâmetros hematológicos em frangos de corte. Arq Inst Biol 70, 419-424.

Çetin E, S Silici, N Çetin, BK Güçlü. 2010. Effects of diets containing different concentrations of propolis on hematological and immunological variables in laying hens. Poult Sci 89, 1703-1708.

Chichlowski M, J Croom, BW McBride, L Daniel, G Davis, MD Koci. 2007. Direct-fed microbial primalac and salinomycin modulate whole-body and intestinal oxygen consumption and intestinal mucosal cytokine production in the broiler chick. Poult Sci 86, 1100-1106.

Chung H, DL Kasper. 2010. Microbiota-stimulated immune mechanisms to maintain gut homeostasis. Curr Opin Immunol 22, 455-460.

Corrier DE, JR DeLoach. 1990. Evaluation of cell-mediated, cutaneous basophil hypersensitivity in young chickens by an interdigital skin test. Poult Sci 69, 403-408.

Dimov V, N Ivanovska, N Manolova, V Bankova, N Nikolov, S Popov. 1991. Immunomodulatory action of propolis. Influence on antiinfectious protection and macrophage function. Apidol 22, 155-162.

Fernandes Jr A, MMR Lopes, V Colombari, ACM Monteiro, EP Vieira. 2006. Atividade antimicrobiana de própolis de Apis mellifera obtidas em três regiões do Brasil. Cienc Rural 36, 294-297.

Ferreira SR, AE Murakami, TGV Siqueira, JMG Santos, A Potença, TC Santos. 2009. Níveis crescentes de parede de levedura sobre a resposta imune celular e perfil hematológico de frangos de corte. Pesq Vet Bras 29, 725-730.

Fischer G, SO Hübner, GD Vargas, T Vidor. 2008. Imunomodulação pela própolis. Arq Inst Biol 75, 247-253.

Fischer G, N Paulino, MC Marcucci, BS Siedler, LS Munhoz, PF Finger, GD Vargas, SO Hübner, T Vidor, PM Roehe. 2010. Green propolis phenolic compounds act as vaccine adjuvants, improving humoral and cellular responses in mice inoculated with inactivated vaccines. Mem Inst Oswaldo Cruz 105, 908-913.

Fonseca FCP, CL Costa. 2010. Influência da nutrição sobre o sistema imune intestinal. CERES: Nutrição \& Saúde 5, 99-110.

Galal A, AM Abd El-Motaal, AMH Ahmed, TG Zaki. 2008ª . Productive performance and immune response of laying hens as affected by dietary propolis supplementation. Int J Poult Sci 7, 272-278.

Galal A, AMH Ahmed, WAH Ali, MH El-Sanhoury, HE Ahmed. 2008 ${ }^{\mathrm{b}}$ Residual feed intake and its effect on cell-mediated immunity in laying hens given different propolis levels. Int J Poult Sci 7, 1105-1111.

Haghighi HR, J Gong, CL Gyles, MA Hayes, B Sanei, P Parvizi, H Gisavi, JR Chambers, S Sharif. 2005. Modulation of antibodymediated immune response by probiotics in chickens. Clin Diagn Lab Immunol 12, 1387-1392.

Kabir SML, MM Rahman, MB Rahman, MM Rahman, SU Ahmed. 2004 The dynamics of probiotics on growth performance and immune response in broilers. Int J Poult Sci 3, 361-364.

Kong XF, YL Lu, YL Yin, GY Wu, R Rui, DY Wang, CB Yang. 2006. Chinese herbal ingredients are effective immune stimulators for chickens infected with the Newcastle disease virus. Poult Sci 85, 2169-2175

Laganá C, AML Ribeiro, FHD Gonzalez, LA Lacerda, SR Terra, PR Barbosa. 2005. Suplementação de vitaminas e minerais orgânicos nos parâmetros bioquímicos e hematológicos de frangos de corte em estresse por calor. Boletim de Indústrial Animal 62, 157-165.

Lustosa SR, AB Galindo, LCC Nunes, KP Randau, PJ Rolim Neto. 2008. Própolis: atualizações sobre a química e a farmacologia. Rev Bras de Farmacogn 18, 447-454.

McCorkle F, I Olah, B Glick. 1980. The morphology of the phytohemagglutinin-induced cell response in the chicken's wattle. Poult Sci 59, 616-623.
Missima F, JM Sforcin. 2008. Green Brazilian propolis action on macrophages and lymphoid organs of chronically stressed mice. eCAM 5, 71-75.

Orsi RO, SRC Funari, AMVC Soares, SA Calvi, SL Oliveira, JM Sforcin, V Bankova. 2000. Immunomodulatory action of propolis on macrophage activation. J Venom Anim Toxins 6, 205-219.

Orsi RO, JM Sforcin, SR Funari, V Bankova. 2005. Effects of Brazilian and Bulgarian propolis on bactericidal activity of macrophages against Salmonella Typhimurium. Int Immunopharm 5, 359-368.

Park YK, SM Alencar, ARP Scamparini, CL Aguiar. 2002. Própolis produzida no sul do Brasil, Argentina e Uruguai: evidências fitoquímicas de sua origem vegetal. Cienc Rural 32, 997-1003.

Pierpoint WS. 2004. The extraction of enzymes from plant tissues rich in phenolic compounds. Methods in Molecular Biology 244, 65-74.

Qureshi MA, RR Dieteri, LD Bacon. 1986. Genetic variation in the recruitment and activation of chicken peritoneal macrophages. In: The Society for Experimental Biology and Medicine. Proceedings $181,560-568$

Rostagno HS, LFT Albino, JL Donzele, PC Gomes, RF Oliveira, DC Lopes, AS Ferreira, SLT Barreto. 2005. Tabelas brasileiras para aves e suínos: composição de alimentos e exigências nutricionais Departamento de Zootecnia, Universidade Federal de Viçosa, MG, Brasil.

SAEG. 1997. Sistemas para Análises Estatísticas e Genéticas-SAEG. Versão 8.0. Universidade Federal de Viçosa, MG, Brasil.

Shahryar HA, M Namvari, H Nourollahi, A Shaddel Tili. 2011. Effect of alcoholic extract propolis on immune system in broiler chickens. J Basic Appl Sci Res 1, 2094-2097.

Shalmany SK, M Shivazad. 2006. The effect of diet propolis supplementation on ross broiler chicks performance. Int $J$ Poult Sci $5,84-88$.

Silva RA, AE Rodrigues, MCM Ribeiro, AR Custódio, NED Andrade, WE Pereira. 2006. Características físico-químicas e atividade antimicrobiana de extratos de própolis da Paraíba, Brasil. Cienc Rural 36, 1842-1848.

SingletonVL, JA Rossi Junior. 1965. Colorimetry of total phenolics whit phosphomolybdic-phosphotungstic acid reagents. Am J Enol Vitic 16, 144-158.

Sousa JPB, NAJC Furtado, R Jorge, AEE Soares, JK Bastos. 2007. Perfis físico-químico e cromatográfico de amostras de própolis produzidas nas microrregiões de Franca (SP) e Passos (MG), Brasil. Rev Bras de Farmacogn 17, 85-93.

Suzuki S, N Shimojo, Y Tajiri, M Kumemura, Y Kohno. 2007. Differences in the composition of intestinal Bifidobacterium species and the development of allergic diseases in infants in rural Japan. Clin Exp Allergy 37, 506-511.

Taheri HR, HR Rahmani, J Pourreza. 2005. Humoral immunity of broilers is affected by oil extracted propolis (OEP) in the diet. Int J Poult Sci 4, 414-417.

Tatli Seven P, I Seven, M Yilmaz, ÜG Simsek. 2008. The effects of Turkish propolis on growth and carcass characteristics in broilers under heat stress. Anim Feed Sci Technol 146, 137-148.

Tatli Seven P, S Yilmaz, I Seven, IH Cerci, MA Azman, M Yilmaz. 2009. Effects of propolis on selected blood indicators and antioxidant enzyme activities in broilers under heat stress. Acta Vet Brno 78, 75-83.

Tekeli A, HR Kutlu, L Celik, F Doran. 2010. Determination of the effects of $Z$. officinale and propolis extracts on intestinal microbiology and histological characteristics in broilers. Int J Poult Sci 9, 898-906.

Toghyani M, M Tohidi, AA Gheisari, SA Tabeidian. 2010. Performance, immunity, serum biochemical and hematological parameters in broiler chicks fed dietary thyme as alternative for an antibiotic growth promoter. Afr J Biotechnol 9, 6819-6825.

Toledo GSP, PTC Costa, LP Silva, D Pinto, P Ferreira, CJ Poletto. 2007. Desempenho de frangos de corte alimentados com dietas contendo antibiótico e/ou fitoterápico como promotores, adicionados isoladamente ou associados. Cienc Rural 37, 1760-1764.

Ziaran HR, HR Rahmani, J Pourreza. 2005. Effect of dietary oil extract of propolis on immune response and broiler performance. Pak $J$ Biol Sci 8, 1485-1490. 